\title{
La incursión de China en el Tratado de Libre Comercio de América del Norte (TLCAN) y sus efectos en el comercio intraindustrial
}

\author{
Jorge Alberto López A., Óscar Rodil M. y Saúl Valdez G.
}

RESUMEN

China se ha convertido en un actor fundamental del comercio mundial. Aunque no ha firmado acuerdos comerciales con los países signatarios del TLCAN, ha ganado terreno como proveedor de bienes logrando grandes avances en esa área. Una de las tendencias dominantes de la integración económica ha sido el desarrollo del comercio intraindustrial, que ha alcanzado altos niveles en los países signatarios del Tratado. En este artículo se analiza el comercio intraindustrial en esta zona de libre comercio, donde la estructura de producción de los países participantes ha cambiado significativamente desde la liberalización del comercio, revelando la internacionalización de las cadenas de producción. Finalmente, se presentan los cambios en la estructura comercial originados por la creciente presencia china en la región del TLCAN, cuyo comercio tiene un esquema similar al de una rueda: Ios Estados Unidos de América como eje central y el Canadá, China y México como radios.

PALABRAS CLAVE

CLASIFICACIÓN JEL

AUTORES
Comercio internacional, China, Estados Unidos, México, TLCAN, tratados, libre comercio, comercio intraindustrial, exportaciones, importaciones, estadísticas comerciales

F14, F15, L16

Jorge Alberto López A. es profesor-investigador titular de economía en la Facultad de Ciencias Sociales de la Universidad Autónoma de Chiapas, México. jalachis@hotmail.com

Óscar Rodil M. es profesor-doctor en la Facultad de Ciencias Económicas y Empresariales de la Universidad de Santiago de Compostela, España. oscar.rodil@usc.es

Saúl Valdez G. es estudiante de maestría en economía en la Facultad de Economía de la Universidad Nacional Autónoma de México (unAm), México. saulvaldez24@hotmail.com 


\section{I}

\section{Introducción}

En este artículo se analiza el patrón del comercio intraindustrial (intercambio de variedades de una misma mercancía) en el contexto de la incursión de China en la zona del Tratado de Libre Comercio de América del Norte (TLCAN). Este país se ha convertido en un actor destacado del comercio mundial, en particular en América del Norte. Si bien este gigante asiático no ha firmado ningún acuerdo comercial con los países signatarios del Tratado, se ha introducido en esta zona y ha ganado terreno como proveedor de bienes. El propósito de este artículo es determinar el significado y las consecuencias de estas tendencias, prestando especial atención al modelo de integración intraindustrial.

Además de analizar los flujos del comercio intraindustrial en el período comprendido entre 1993 y 2011, este estudio se vincula con el debate teórico sobre el establecimiento de zonas económicas. Estos procesos de integración han dado lugar a una intensa controversia teórica acerca de sus efectos en el comercio. Durante mucho tiempo, autores pioneros como J. Viner (1950) y Dornbusch (1992) han sostenido que los países miembros de las zonas económicas han incrementado su bienestar a expensas del resto del mundo. En un caso como el del TLCAN, la reducción de las barreras internas podría impulsar la competitividad de los países miembros, acrecentando la eficiencia relativa de la zona económica del Tratado y de las importaciones y exportaciones entre sus miembros. Por lo tanto, suponiendo la existencia de economías de escala, externalidades y ventajas comparativas dinámicas, las importaciones entre los miembros de la zona reemplazarían a las del resto del mundo. Sin embargo, la evidencia empírica sugiere que los Estados Unidos de América han perdido cuota de mercado en México (Dussel y Gallagher, 2013), aunque esto obedece principalmente a las piezas y componentes de origen chino (Gazol, 2007) que ganaron participación en el mercado mexicano en los últimos años ${ }^{1}$.

En lo que respecta al debate acerca de los efectos del proceso de integración, existen distintas teorías económicas, pero no se ha dado ninguna respuesta definitiva sobre el impacto regional del proceso, dado que las consecuencias varían dependiendo del enfoque teórico adoptado (Rodríguez-Pose y Petrakos, 2004). En consecuencia, se requiere un análisis empírico para determinar los principales cambios económicos ligados al proceso del TLCAN y, en particular, para demostrar la forma en que China se ha integrado en la zona como proveedor de bienes.

El artículo se desarrolla de acuerdo a la siguiente estructura: en la sección II se aborda el comercio intraindustrial, así como su conceptualización y aspectos relativos a la metodología. La sección III se refiere a la incursión de China en el TLCAN y sus repercusiones en el ámbito de la complementariedad y la competencia. La globalización, la reestructuración y los modelos de integración en el mercado mundial de dos economías emergentes, como las de China y México, son los temas tratados en la sección IV. En tanto que la emergencia de China en América de Norte y los cambios del modelo de comercio intraindustrial en el TLCAN son abordados en la quinta sección. Finalmente, en la sección VI se entregan las principales conclusiones del estudio.

\footnotetext{
1 Por eso se realizaron las sucesivas revisiones al anexo 401 del TLCAN, con el fin de relajar las normas de origen; solo se cambió la ubicación geográfica de los proveedores, pero estos siguen siendo los mismos (Gazol, 2007).
} 


\section{II}

\section{El comercio intraindustrial: conceptualización y aspectos metodológicos}

Desde el punto de vista teórico, el problema del comercio intraindustrial se planteó en la década de 1960 con los estudios de Verdoorn (1960); Balassa (1963), y Grubel (1967). Estos autores descubrieron que una proporción creciente del comercio se producía en las mismas industrias y en los mismos sectores. Esta nueva forma de comercio internacional condujo al concepto económico actualmente denominado comercio intraindustrial.

Otros autores como Krugman (1995) o Grossman y Helpman (1990) analizaron el comercio intraindustrial y encontraron notables desarrollos basados en las nuevas teorías de comercio internacional. La teoría moderna del comercio brinda una serie de elementos explicativos que se centran en la competencia imperfecta, las economías de escala y las diferentes variedades de productos. El comercio intraindustrial surge como resultado de los rendimientos crecientes, la diferenciación de productos y las diversas preferencias de los consumidores. En primer lugar, las economías de escala promueven la concentración de la producción en respuesta a las grandes demandas de un pequeño número de centros productivos. Segundo, cada empresa puede diferenciar sus productos ante compañías rivales a fin de segmentar la demanda y mantener un grado de monopolio sobre su propia variedad. En tercer lugar, la existencia de una masa de consumidores con diferentes preferencias respecto de las múltiples variedades de productos ofrecidas es esencial para el comercio intraindustrial. Estas tres condiciones tienden a hacerse más visibles en el caso de las economías desarrolladas, lo que explica por qué algunas zonas de integración, como la Unión Europea, han tenido tan buen desempeño en esos intercambios.

Ha habido varios procesos paralelos al aumento del comercio intraindustrial que, en cierto sentido, fueron originados por este. El avance de la liberalización del comercio, sobre todo de los productos industriales, tuvo lugar tanto a nivel global, con el Acuerdo General sobre Aranceles Aduaneros y Comercio (GATT) y la Organización Mundial del Comercio (OMC), como regionalmente, mediante la Unión Europea, el TLCAN, la Asociación de Naciones de Asia Sudoriental (ASEAN), el Mercado Común del Sur (Mercosur) y el Mercado Común Centroamericano (MCCA). Estos procesos han recibido el impulso de la expansión del comercio intrafirma orientado a la libre circulación de bienes intermedios y finales favorable para las corporaciones multinacionales. Algunos autores (Navaretti, Haaland y Venables, 2002; OCDE, 2002; Helpman, 2006) introdujeron este último aspecto en el análisis del comercio intraindustrial, centrándose en el papel de las multinacionales. Según estos autores, las empresas multinacionales son las verdaderas protagonistas del actual proceso de globalización.

En síntesis, es posible identificar tres modelos de comercio intraindustrial: el basado en la diferenciación de productos y economías de escala (el más común); el modelo de bienes funcionalmente homogéneos (estrechamente relacionado con el comercio transfronterizo y con el comercio periódico o de temporada), y el modelo basado en la brecha tecnológica, el ciclo de vida de los productos y la internacionalización del proceso productivo (intrafirma).

Otra perspectiva es la diferenciación entre el comercio intraindustrial vertical y el horizontal. El comercio intraindustrial horizontal tiene lugar cuando dos cadenas productivas independientes de la misma industria y con un nivel de desarrollo similar intercambian mercancías a nivel internacional. El vertical ocurre cuando la misma línea de producción se ubica en diferentes países, lo que conduce a la reexportación de bienes (Dussel y León González, 2001).

Desde un punto de vista metodológico, se han elaborado varios indicadores para medir la presencia del comercio intraindustrial en distintas economías, siendo el más común el índice de Grubel y Lloyd (IGL) ${ }^{2}$, construido sobre la base de los flujos del comercio bilateral entre países. Estos flujos pueden dividirse en dos grupos: el comercio interindustrial (bienes distintos) y el comercio intraindustrial (bienes similares). El IGL se representa con valores en el rango del 0 al 1 , dependiendo de la ausencia $(\mathrm{IGL}=0)$ o la ocurrencia plena $(\mathrm{IGL}=1)$

\footnotetext{
2 La fórmula del índice agregado de Grubel y Lloyd es: IGL $=1-\left[\sum\left|x_{i}-m_{i}\right| / \sum\left(x_{i}+m_{i}\right)\right]$, donde $x_{i}$ y $m_{i}$ representan el valor de las exportaciones e importaciones del sector $i$, respectivamente. La versión corregida del índice agregado de Grubel y Lloyd se expresa de la siguiente manera: $\mathrm{IGL}_{\text {corregido }}=\left[\sum\left(\mathrm{x}_{\mathrm{i}}+\mathrm{m}_{\mathrm{i}}\right)-\sum\left|\mathrm{x}_{\mathrm{i}}-\mathrm{m}_{\mathrm{i}}\right|\right] /\left[\Sigma\left(\mathrm{x}_{\mathrm{i}}+\mathrm{m}_{\mathrm{i}}\right)\right.$ $\left.\left|\sum \mathrm{x}_{\mathrm{i}}-\sum \mathrm{m}_{\mathrm{i}}\right|\right]$, donde $\mathrm{x}_{\mathrm{i}} \mathrm{y} \mathrm{m}_{\mathrm{i}}$ representan el valor de las exportaciones e importaciones del sector $i$, respectivamente.
} 
de comercio intraindustrial ${ }^{3}$. A menudo, se utiliza una expresión ajustada alternativa del IGL a nivel agregado para evitar el efecto desestabilizador de la balanza comercial ${ }^{4}$. Asimismo, otros autores (Cárdenas y Dussel, 2011) utilizan un índice propuesto por Hamilton y Kniest (1991) que mide el comercio intraindustrial marginal, en lo que respecta al comercio total agregado.

Un punto importante que destacar es que el grado de desagregación de datos afecta a la medición del comercio

\footnotetext{
${ }^{3}$ La versión agregada del IGL es: IGL $=1-\left[\sum\left|\mathrm{x}_{\mathrm{i}}-\mathrm{m}_{\mathrm{i}}\right| / \Sigma\left(\mathrm{x}_{\mathrm{i}}+\mathrm{m}_{\mathrm{i}}\right)\right]$, donde

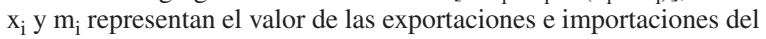
sector $i$, respectivamente.

${ }^{4}$ La versión corregida de la versión agregada del IGL se expresa como $\mathrm{IGL}_{\text {corregido }}=\left[\sum\left(\mathrm{x}_{\mathrm{i}}+\mathrm{m}_{\mathrm{i}}\right)-\sum\left|\mathrm{x}_{\mathrm{i}}-\mathrm{m}_{\mathrm{i}}\right|\right] /\left[\sum\left(\mathrm{x}_{\mathrm{i}}+\mathrm{m}_{\mathrm{i}}\right)-\left|\sum \mathrm{x}_{\mathrm{i}}-\sum \mathrm{m}_{\mathrm{i}}\right|\right]$, donde $\mathrm{x}_{\mathrm{i}}$ y $\mathrm{m}_{\mathrm{i}}$ representan el valor de las exportaciones e importaciones del sector $i$, respectivamente.
}

intraindustrial. Es mejor utilizar la mayor desagregación sectorial posible para identificar con precisión los flujos de comercio intraindustrial. Las estadísticas empleadas en este estudio brindan un desglose sectorial completo a nivel de dos dígitos (capítulos arancelarios) del Sistema Armonizado de Designación y Codificación de las Mercancías, con información procedente de la base de datos COMTRADE de las Naciones Unidas. La información a nivel de cuatro dígitos (partidas) solo se utiliza en el caso de los capítulos en que se observa una mayor intensidad de comercio intraindustrial.

Por otra parte, cabe destacar que en este artículo se analiza el comercio entre países con niveles de desarrollo muy distintos, por ejemplo, entre los Estados Unidos de América o el Canadá, por una parte, y China o México, por otra. Por ello permite considerar varios modelos de comercio, como el Norte-Norte, el Norte-Sur y el Sur-Sur.

\section{III}

\section{La incursión de China en el TLCAN: entre la complementariedad y la competencia}

Antes de la década de 1990, China había mostrado poco interés en firmar acuerdos formales y participar en el comercio regional; esto se debía en parte a que el país aún no estaba listo para afrontar la rápida liberalización del comercio y la inversión. Sin embargo, con la llegada del siglo XXI, la actitud de China hacia la cooperación regional cambió drásticamente (Wang, 2004, citado en Yu, Xue y Hong, 2006). Su entrada en la OMC la obligó a asumir varios compromisos en términos de liberalización del mercado y la integró en la economía mundial (Yu, Xue y Hong, 2006). Hasta el momento, China ha firmado 10 tratados de libre comercio con 24 países, incluidos 3 de América Latina (Chile, Costa Rica y Perú). Otros tres acuerdos de libre comercio (con Australia, Noruega y Suiza, respectivamente) se hallan en curso de negociación (omc, 2013).

Desde un punto de vista teórico, uno de los principales argumentos señalados en relación con los acuerdos de libre comercio es que tienen como meta mejorar la dinámica económica de los países signatarios. Sin embargo, una característica de los países del TLCAN es que, si bien ninguno de ellos ha firmado un tratado de libre comercio con China, el comercio con ese país está creciendo rápidamente, especialmente en el caso de los Estados Unidos de América. De hecho, China ha surgido como el principal proveedor del mercado estadounidense, reemplazando a México en 2003 y al Canadá en 2009 (véase el gráfico 1), y como el segundo proveedor del mercado en México desde 2002, desplazando al Canadá (véase el gráfico 2).

Si se analiza el coeficiente de cobertura (definido como el porcentaje del comercio realizado en el marco de acuerdos con respecto al total del comercio), este se ubica en $11,2 \%$ en el caso de China; $34,4 \%$ para los Estados Unidos de América; 68,4\% para el Canadá y 81,5\% para México (Rosales y Kuwayama, 2012) (véase el cuadro 1). Como demuestran estos datos, China no ha necesitado tratados de libre comercio para convertirse en una potencia del comercio mundial. 
GRÁFICO 1

Estados Unidos de América: importaciones desde China y sus socios comerciales en relación con el total de importaciones, 1993-2011

(En porcentajes)

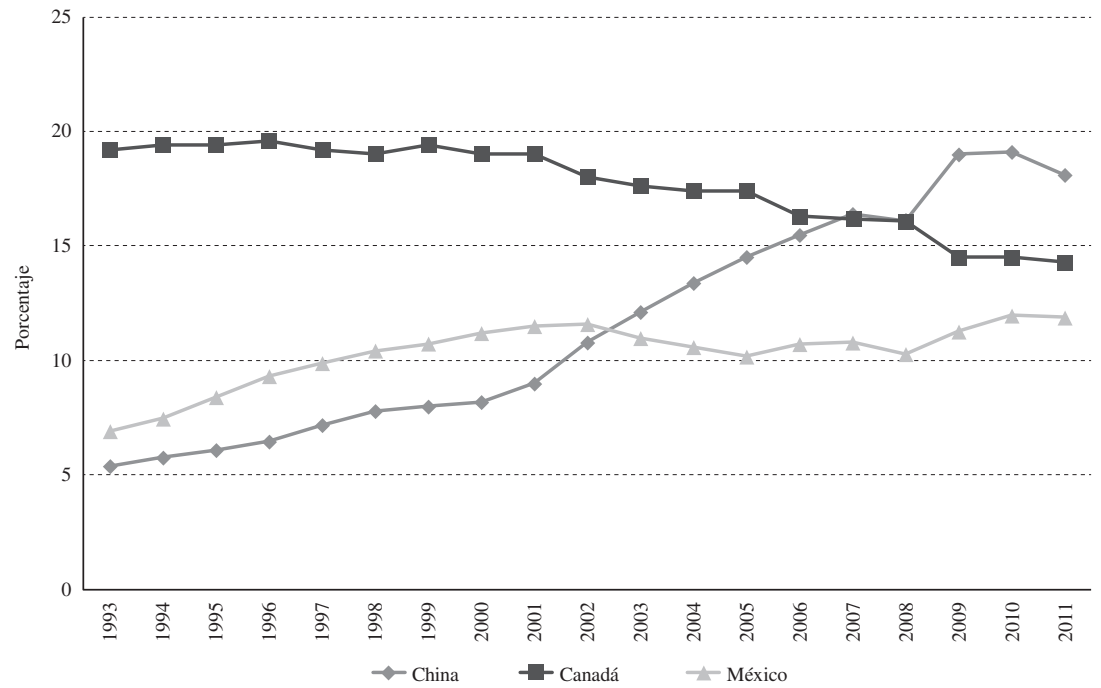

Fuente: Oficina del Censo de los Estados Unidos [en línea] http://www.census.gov/foreign-trade/statistics/country/, 2013.

GRÁFICO 2

México: importaciones desde China y sus socios comerciales en relación con el total de importaciones, 1993-2011

(En porcentajes)

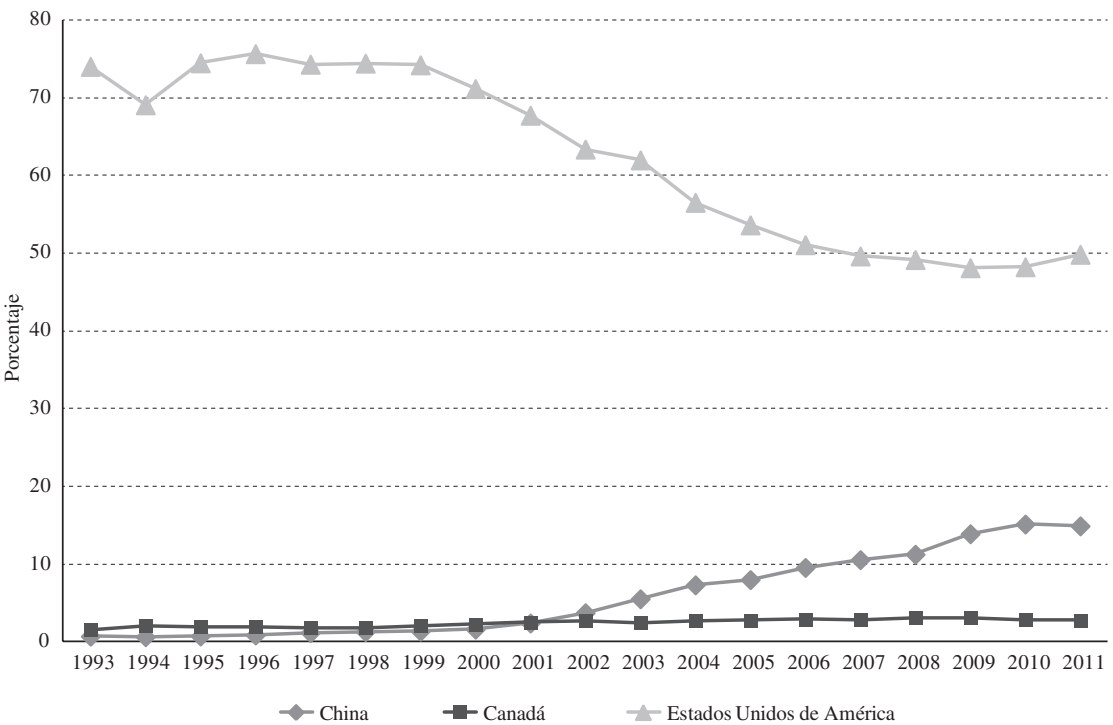

Fuente: elaboración propia a partir de la base de datos comtrade de las Naciones Unidas. 
CUADRO 1

Países del TLCAN ${ }^{\mathrm{a}}$ y China: coeficiente de cobertura de los acuerdos comerciales, 2009

(En porcentajes)

\begin{tabular}{lccc}
\hline \multirow{2}{*}{ País } & \multicolumn{3}{c}{ Cobertura de tratados de libre comercio } \\
\cline { 2 - 4 } & Exportaciones e importaciones & Exportaciones & Importaciones \\
\hline Estados Unidos & 34,4 & 40,1 & 30,5 \\
Canadá & 68,4 & 77,7 & 59,2 \\
México & 81,5 & 93,0 & 70,2 \\
China & 11,2 & 10,1 & 12,6 \\
\hline
\end{tabular}

Fuente: Organización Japonesa para el Comercio Exterior (JETRO), 2010 JETRO Global Trade and Investment Report. A Global Strategy for Japanese Companies to Open New Frontiers in Overseas Markets, Tokio, 2010; y O. Rosales y M. Kuwayama, China y América Latina y el Caribe. Hacia una relación económica y comercial estratégica, Libros de la CEPAL, N 114 (LC/G.2519-P), Santiago de Chile, Comisión Económica para América Latina y el Caribe (CEPAL), marzo de 2012. Publicación de las Naciones Unidas, $N^{\circ}$ de venta: S.12.II.G.2.

a Tratado de Libre Comercio de América del Norte.

Los analistas tienen opiniones encontradas respecto de si el papel de China y México en el mercado estadounidense es competitivo o complementario. Algunos autores, como Feenstra y Looi Kee (2009), estiman que existe una competencia creciente entre estos dos países por el mercado estadounidense y que la inversión extranjera directa (IED) ha ido cambiando de dirección hacia China en detrimento de México (De la Cruz, Núñez y Ruiz-Porras, 2008, citados en De la Cruz y Marín, 2011). Feenstra y Looi Kee (2009) argumentan también que la diferencia entre México y China es que el primero recortó sus aranceles en un grado excesivo, mientras que China hizo lo mismo unilateralmente, protegiendo algunos rubros como la agricultura. No obstante, Neme (2006) afirma que las manufacturas mexicanas no compiten con China en el mercado estadounidense, pero que cada país tiene su propio nicho de acuerdo con los modelos de especialización que surgieron en la década de 1990.

Resulta de especial interés en este artículo el análisis del comercio intraindustrial, que debería clarificar en qué grado estas economías son complementarias o competitivas. Este tema se presenta con total conocimiento del hecho de que China se ha convertido en una de las principales potencias del mundo, pero especialmente en la zona de América del Norte.

\section{La globalización y la reestructuración: modelos de integración de dos economías emergentes, China y México, en el mercado mundial}

A comienzos de la década de 1980, México mostraba una apertura limitada. De hecho, en 1983, casi todas sus importaciones estaban sujetas a permiso previo (barreras no arancelarias) y a aranceles extremadamente elevados. Sin embargo, desde ese año, México ha reestructurado su economía con el fin de lograr tres objetivos: sólidas finanzas públicas, privatización de empresas estatales y liberalización del comercio. La racionalización de la protección comercial transformó la economía del país de una de las más cerradas a una de las más abiertas del mundo. La apertura fue tal que en 2006 solo un $4,1 \%$ del valor del sector no maquilador y un $2,7 \%$ del total de importaciones requería de permiso previo. Además, el promedio de los aranceles, que era del $27 \%$ en 1982 , descendió a un 5,9\% en agosto de 2012 (el arancel ponderado en 1982 era del 16,4\%, pero en 
2012 apenas alcanzaba a un 0,56\%) (CEFP, 2006; Gaceta Parlamentaria, 2012) $)^{5}$. Un claro ejemplo de este proceso es el incremento del coeficiente de apertura, que pasó del 30\% al 81\% entre 1993 y 2011 (véase el gráfico 3).

En resumen, esto evidencia la acelerada liberalización de la economía mexicana, que se refleja en su creciente apertura, la reducción de aranceles y la eliminación de las barreras no arancelarias. De hecho, tras estos cambios, la concentración del comercio exterior de México con los Estados Unidos de América equivalía a dos tercios del total del comercio actual de México (si bien en algunos años ha representado más del 70\%). Esta concentración se profundizó durante el proceso del TLCAN hasta la recesión de 2001 y el ingreso de China a la OMC ese mismo año, lo que había mitigado el efecto de este fenómeno.

En tanto, desde 1978 China ha implementado una serie de reformas que comenzaron con las cuatro modernizaciones propuestas por Deng Xiaoping: la agricultura, la industria, la defensa y la ciencia, y la tecnología (Neme, 2006). La política de economía abierta condujo a la adopción de un marco legal para facilitar

\footnotetext{
${ }^{5}$ Gazol (2007) analiza el retorno a una nueva etapa de proteccionismo que permitía compras en el exterior equivalentes a un 2,2\% en 1995 y al $10 \%$ y al $11 \%$ en 2005 y 2006, respectivamente. Sin embargo, este modelo difiere del que prevalecía en la década de 1980.
}

las relaciones económicas internacionales y la inversión extranjera directa, la creación de zonas económicas especiales y ciudades abiertas para modernizar la industria nacional, estableciendo empresas extranjeras que elaboran y exportan productos con la ayuda de diversos incentivos (Neme, 2006, págs. 30 y 31). Un claro signo de este proceso de reformas es la creciente apertura económica de China desde 1993, que pasó del $30 \%$ en ese año al 77\% en 2011 (véase el gráfico 3).

En este contexto de apertura y reforma, China y México se transformaron en protagonistas destacados de la economía mundial, logrando grandes avances en la exportación de manufacturas. China comenzó a ser parte importante de la "fábrica mundial" cuando su cuota de exportaciones mundiales creció de un $2,8 \%$ en 1993 al 15,4\% en 2011. En tanto, la cuota de México se incrementó de un 0,60\% en 1993 al 2,0\% en 2011, y de este modo el país se convirtió en el principal exportador latinoamericano de manufacturas y en un actor relevante de la "fábrica mundial"6.

En consecuencia, China se convirtió en los últimos años en un actor fundamental a nivel mundial y hoy en día es una potencia económica regional en Asia. Sin lugar

\footnotetext{
${ }^{6}$ Cálculos sobre la base de datos de Indicadores del Desarrollo Mundial
} del Banco Mundial, medidos en dólares corrientes.

México y China: grado de apertura de la economía, 1993-2011

(En porcentajes sobre el PIB, sobre la base de dólares a precios constantes de 2000)

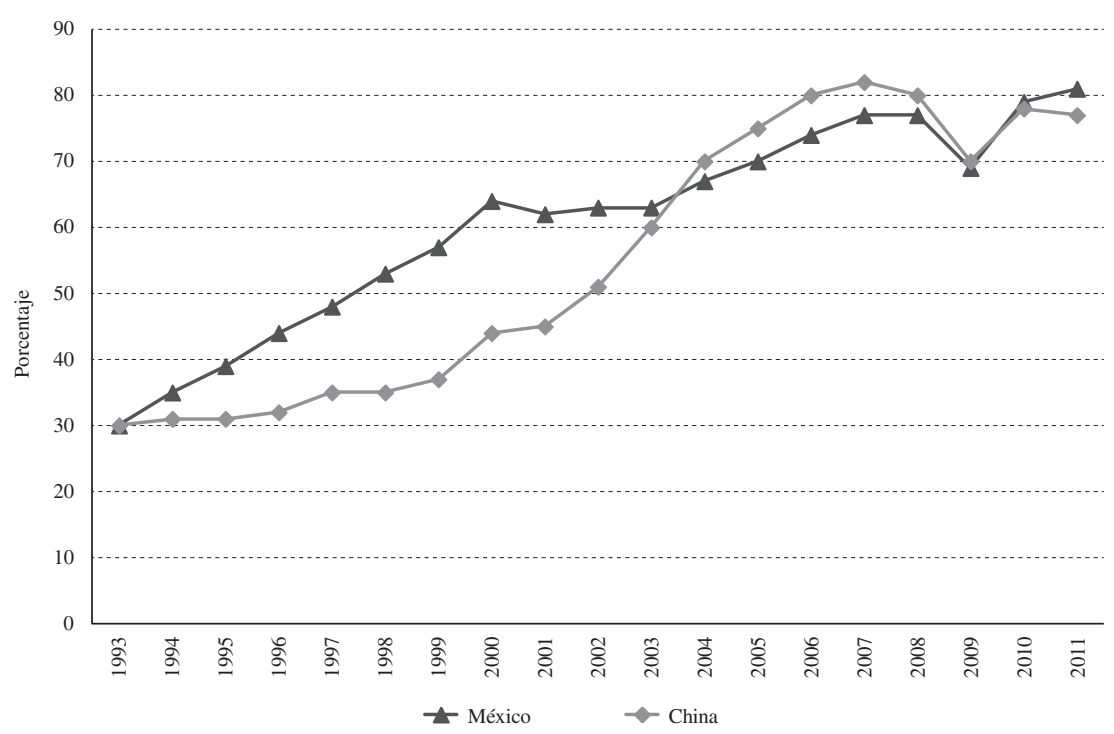

Fuente: elaboración propia sobre la base de datos de Indicadores del Desarrollo Mundial del Banco Mundial. 
a dudas, es actualmente una potencia mundial de primer orden. La participación de China en las exportaciones mundiales de manufactura sobrepasó a las de todos los miembros del TLCAN en conjunto, lo que convierte al país en una parte gravitante de la "fábrica mundial" (véase el gráfico 4).

GRÁFICO 4

China y países miembros del TLCAN ${ }^{\text {a: }}$ exportaciones de manufacturas, 1993-2011 (En porcentajes del total mundial)

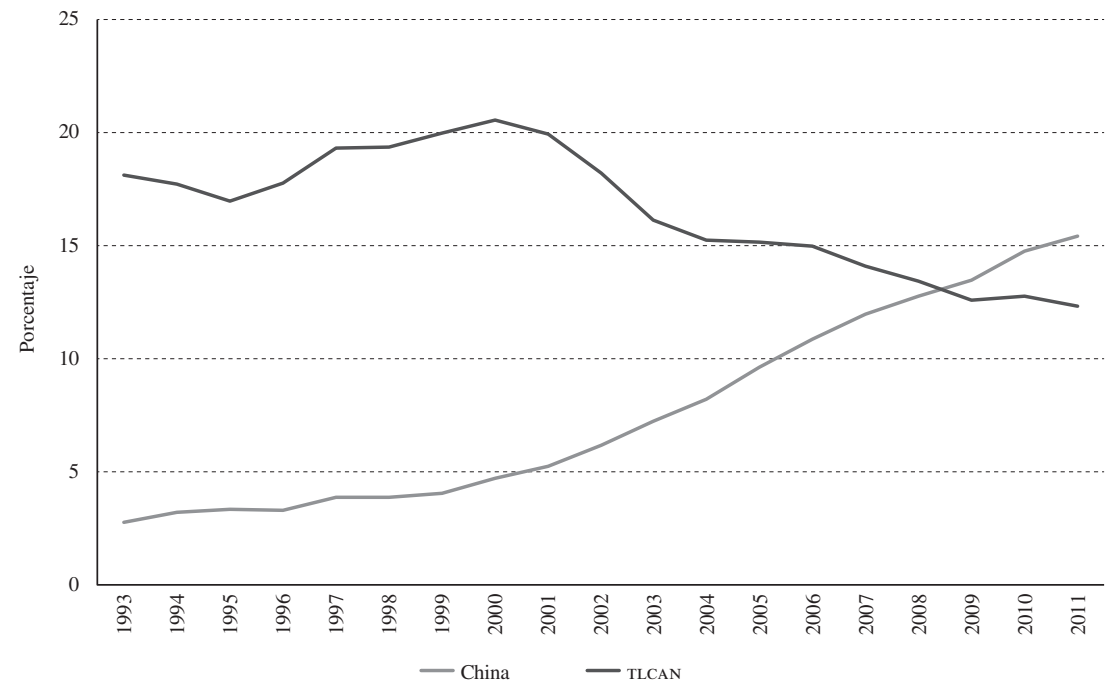

Fuente: elaboración propia sobre la base de datos de Indicadores del Desarrollo Mundial del Banco Mundial.

a Tratado de Libre Comercio de América del Norte.

\section{La incursión de China en América del Norte y los cambios del modelo de comercio intraindustrial en el TLCAN}

Desde una perspectiva empírica, en este artículo se procura analizar el modelo del comercio intraindustrial durante un período marcado por el proceso de integración en América del Norte (TLCAN) y la incursión de China en esa región. En estudios previos (Dussel y León González, 2001; OCDE, 2002; López y Rodil, 2008; Dussel y Trápaga, 2007; Cárdenas y Dussel, 2011; Rodil y López, 2011; Neme, 2006) se demostró la existencia de un comercio intraindustrial creciente entre México y el mundo exterior, particularmente los Estados Unidos de América. Sin embargo, hay desacuerdo en lo que respecta a China. Algunos autores, incluido Neme (2006), afirman que, si bien es obvia la competencia real entre México y China en algunos grupos de productos, no hay un claro ganador y las exportaciones mexicanas al mercado estadounidense no están desplazadas por las exportaciones chinas. En cambio, otros autores, incluidos Cárdenas y Dussel (2011) y Dussel y Gallagher (2013), sostienen que el comercio de México con los Estados Unidos de América y China refleja una débil integración con China y una mayor, aunque decreciente, integración con los Estados Unidos de América. En tanto, otros autores (De la Cruz y Marín, 2011) opinan, sobre la base de un análisis de causalidad, que los datos estadísticos apuntan a una relación negativa entre el comercio de China y México en el mercado estadounidense, de modo que México debería tratar de evitar el desplazamiento de su comercio. 
Teniendo en cuenta esta situación, en el presente estudio se incluye un enfoque diferente, donde se explora el fenómeno del comercio intraindustrial entre China y México en la región del TLCAN, complementando el análisis anterior para lograr una mayor comprensión de las tendencias a nivel agregado. De este modo, se estudian diferentes modelos de comercio: Norte-Norte (los Estados Unidos de América con el Canadá), Norte-Sur (los Estados Unidos de América y el Canadá con México y China), y Sur-Sur (México con China). El presente estudio se enfoca en esas relaciones considerando que el papel de los Estados Unidos de América es crucial en la región del TLCAN.
El comercio intraindustrial se desarrolló en el marco de un intenso proceso de integración entre México, los Estados Unidos de América y el Canadá, en un momento en que la participación de China en las importaciones del TLCAN estaba aumentando. El elevado crecimiento del comercio y la concentración de las exportaciones e importaciones en un reducido número de rubros en el intercambio de México y China con el mercado estadounidense revela un modelo comercial dominado por un pequeño grupo de sectores y la aparición de China en la región del TLCAN, como proveedor y como cliente, pero especialmente como proveedor (véase el gráfico 5).

GRÁFICO 5

China: balanza comercial con la región del $\operatorname{TLCAN}^{\mathrm{a}}, 1993-2011$

(En millones de dólares)

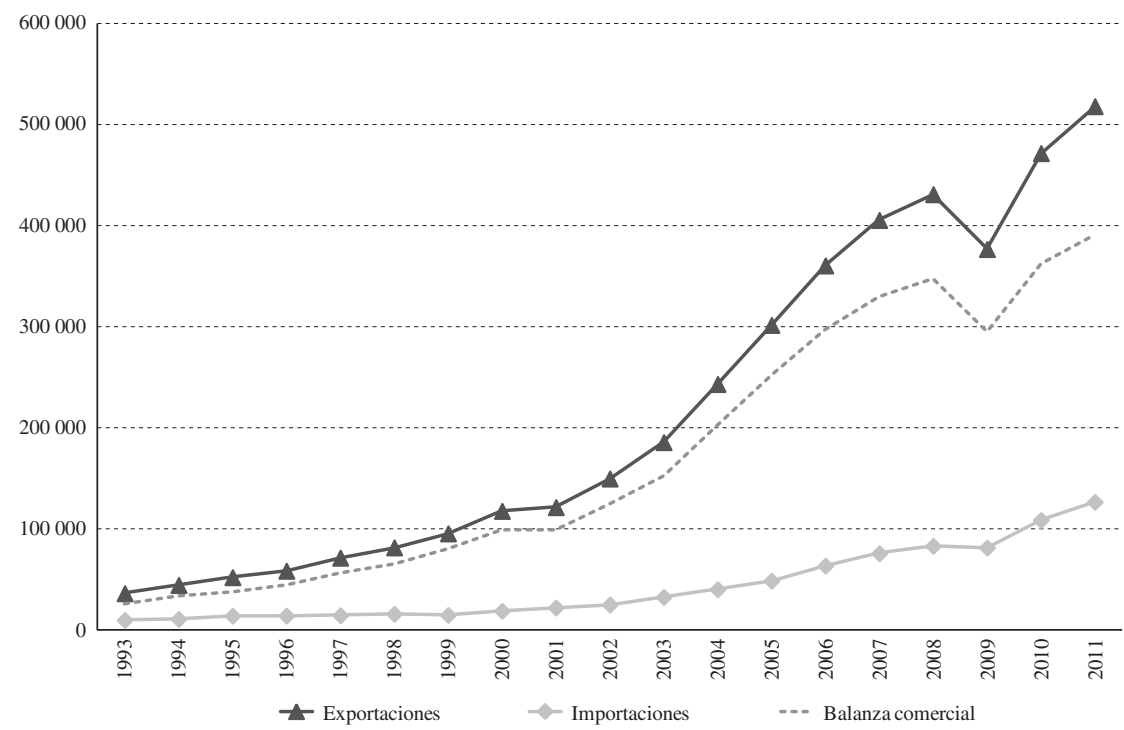

Fuente: elaboración propia a partir de la base de datos comtrade de las Naciones Unidas.

a Tratado de Libre Comercio de América del Norte.

Más específicamente, puede observarse que el comercio de China con los países del TLCAN está bastante concentrado en solo cinco capítulos. En términos de exportaciones, cinco capítulos representan un $63,0 \%$ de las exportaciones chinas al mercado estadounidense, un 59,8\% de las destinadas al Canadá y un 77,6\% a México. En cuanto a las importaciones, los cinco capítulos principales representan un $45,3 \%$ de las provenientes de los Estados Unidos de América, un 52,8\% de las del Canadá y un $81,6 \%$ de las procedentes de México (véanse los cuadros 2 y 3). La balanza comercial en los cinco capítulos principales es favorable a China en comparación con los Estados Unidos de América y México, pero deficitaria respecto del Canadá ${ }^{7}$. En términos de las exportaciones, China muestra un claro superávit con todos los países del TLCAN en los cinco capítulos principales. En otras palabras, tiene un superávit de manufacturas, pero presenta un déficit en materia de recursos naturales y productos primarios.

\footnotetext{
${ }^{7}$ El comercio entre China y el Canadá no se analiza en detalle en este estudio. Basta con decir que se trata en su mayoría de comercio interindustrial, basado en las clásicas ventajas relativas a los recursos.
} Además, su repercusión en el comercio de México es insignificante. 
CUADRO 2

China: productos con mayor peso relativo en las exportaciones al Canadá, los Estados Unidos de América y México, 2011

(Tasas medias de crecimiento anual, en porcentajes)

\begin{tabular}{|c|c|c|c|c|c|c|c|}
\hline \multirow{2}{*}{ Capítulo } & \multirow{2}{*}{ Producto } & \multicolumn{2}{|c|}{ Estados Unidos } & \multicolumn{2}{|c|}{ Canadá } & \multicolumn{2}{|c|}{ México } \\
\hline & & 2011 & $1993-2011$ & 2011 & 1993-2011 & 2011 & 1993-2011 \\
\hline 84 & Artefactos mecánicos, calderas y partes & 23,9 & 25,7 & 19,8 & 28,9 & 24,8 & 29,6 \\
\hline 85 & Máquinas y equipo eléctrico & 23,8 & 18,6 & 24,3 & 22,7 & 43,4 & 38,5 \\
\hline 95 & Juguetes, juegos y artículos para recreo & 5,7 & 9,7 & 5,6 & 13,3 & 2,5 & 26,9 \\
\hline 94 & Muebles, equipo quirúrgico, n.e.p. & 5,4 & 17,6 & 5,7 & 20,0 & $\ldots$ & $\ldots$ \\
\hline 64 & Calzado, polainas y artículos análogos & 4,2 & 7,5 & $\ldots$ & $\ldots$ & $\ldots$ & $\ldots$ \\
\hline 62 & Prendas de vestir que no sean de punto & $\ldots$ & $\ldots$ & 4,4 & 11,3 & $\ldots$ & $\ldots$ \\
\hline 90 & Instrumentos ópticos, fotográficos y médicos & $\ldots$ & $\ldots$ & $\ldots$ & $\ldots$ & 4,4 & 36,6 \\
\hline 76 & Aluminio y artículos similares & $\ldots$ & $\ldots$ & $\ldots$ & $\ldots$ & 2,5 & 56,1 \\
\hline & Total seleccionado & 63,0 & 16,5 & 59,8 & 20,0 & 77,6 & 33,8 \\
\hline
\end{tabular}

Fuente: elaboración propia a partir de la base de datos COMTRADE de las Naciones Unidas.

n.e.p.: no especificados en otra parte.

CUADRO 3

China: productos con mayor peso relativo en las importaciones procedentes del Canadá, los Estados Unidos de América y México, 2011

(Tasas medias de crecimiento anual, en porcentajes)

\begin{tabular}{|c|c|c|c|c|c|c|c|}
\hline \multirow{2}{*}{ Capítulo } & \multirow{2}{*}{ Producto } & \multicolumn{2}{|c|}{ Estados Unidos } & \multicolumn{2}{|c|}{ Canadá } & \multicolumn{2}{|c|}{ México } \\
\hline & & 2011 & 1993-2011 & 2011 & 1993-2011 & 2011 & $1993-2011$ \\
\hline 84 & Artefactos mecánicos, calderas y partes & 11,8 & 11,2 & $\ldots$ & $\ldots$ & $\ldots$ & $\ldots$ \\
\hline 12 & Semillas y frutos oleaginosos, semillas y & & & & & & \\
\hline & frutos diversos & 10,3 & 39,9 & 5,5 & 33,9 & $\ldots$ & $\ldots$ \\
\hline 85 & Máquinas y equipo eléctrico & 9,7 & 14,4 & $\ldots$ & $\ldots$ & 5,8 & 30,7 \\
\hline 99 & Productos no especificados & 7,0 & 28,3 & $\ldots$ & $\ldots$ & $\ldots$ & $\ldots$ \\
\hline 87 & Tractores y piezas & 6,5 & 12,5 & $\ldots$ & $\ldots$ & 14,9 & $\infty$ \\
\hline 26 & Minerales metalíferos, escorias y cenizas & $\ldots$ & $\ldots$ & 15,5 & 27,7 & 26,1 & \\
\hline 47 & Pasta de madera y sus derivados & $\ldots$ & $\ldots$ & 15,4 & 20,6 & $\ldots$ & $\ldots$ \\
\hline 44 & Madera, carbón vegetal y manufacturas & & & & & & \\
\hline & de madera & $\ldots$ & $\ldots$ & 8,7 & 23,3 & $\ldots$ & $\ldots$ \\
\hline 27 & Petróleo y productos del petróleo & $\ldots$ & $\ldots$ & 7,8 & 26,8 & 22,4 & $\infty$ \\
\hline 74 & Cobre y sus manufacturas & $\ldots$ & $\ldots$ & $\ldots$ & $\ldots$ & 12,3 & 91,7 \\
\hline & Total seleccionado & 45,3 & 15,3 & 52,8 & 24,3 & 81,6 & 51,3 \\
\hline
\end{tabular}

Fuente: elaboración propia a partir de la base de datos COMTRADE de las Naciones Unidas.

$\infty$ : se refiere al valor infinito, ya que es el resultado de calcular la tasa de crecimiento partiendo de cero en el año 1993.

Si bien los Estados Unidos son el principal socio comercial de China, México experimentó un significativo aumento relativo en sus relaciones comerciales con este país asiático. Algunos productos en particular desempeñan un papel preponderante en esta relación entre México y China, como los capítulos 84 y 85 , que constituyen el 49,4\% de las exportaciones de China a la región del TLCAN, mientras que las importaciones procedentes de los países del TLCAN muestran una mayor dispersión (estos dos capítulos solo forman el $19 \%$ de esas importaciones).

Con respecto al índice de comercio intraindustrial o índice de Grubel y Lloyd (IGL) de China, el efecto desestabilizador de la balanza comercial en las relaciones con los países del TLCAN debería tenerse en cuenta mediante el cálculo del IGL ajustado, como se ha indicado anteriormente (véase el gráfico 6). El IGL correspondiente al comercio de China con los Estados Unidos pasó del 0,58 en 1993 al 0,63 en 2011. En el caso del comercio de China con México, el IGL ajustado se redujo del 0,63 en 1993 al 0,41 en 2011. Finalmente, el IGL relativo al comercio de China con el Canadá era de solo 0,43 en 1993 y retrocedió a 0,29 en 2011.

Del gráfico 6 se pueden sacar al menos tres conclusiones fundamentales. En primer lugar, los 
GRÁFICO 6

China: comercio intraindustrial con los países del TLCAN ${ }^{\mathrm{a}}, 1993-2011$ (En valores del índice de Grubel y Lloyd)

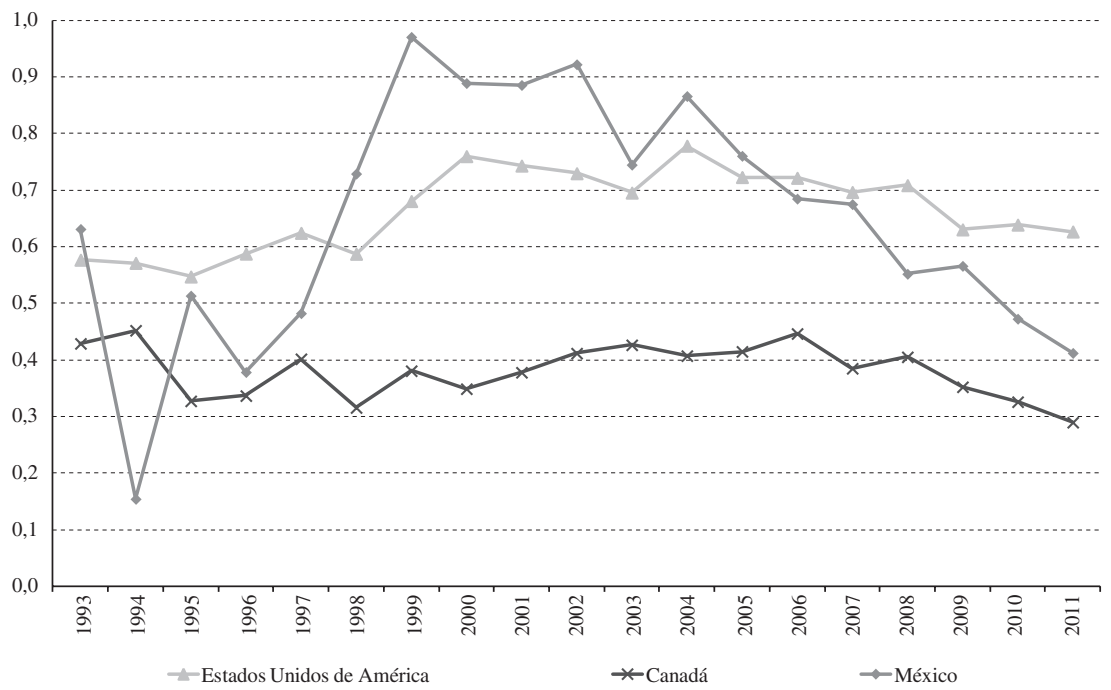

Fuente: elaboración propia a partir de la base de datos COMTRADE de las Naciones Unidas.

a Tratado de Libre Comercio de América del Norte.

niveles de comercio intraindustrial entre China y los países del TLCAN son relativamente bajos, especialmente en comparación con los patrones observados en las economías desarrolladas (generalmente por encima del $60 \%$ o el $70 \%$ del comercio total). Estos datos muestran que la emergencia de China en la región del TLCAN está vinculada a la "fábrica mundial", pero no alcanza una integración industrial completa. De hecho, el comercio intraindustrial se concentra solo en un par de sectores. En segundo lugar, China tiende a registrar un nivel más alto de comercio intraindustrial con los Estados Unidos de América que con México o con el Canadá. Este hecho muestra el papel dominante que desempeña esta economía como "fábrica mundial" y que intensifica los flujos de comercio intraindustrial con la mayoría de sus socios comerciales. Como resultado, las relaciones entre sus socios comerciales tienen un papel secundario, como en el caso del comercio Sur-Sur entre China y México o el comercio Norte-Sur entre el Canadá y China. En tercer lugar, el comercio intraindustrial entre China y los países del TLCAN ha registrado una tendencia a la baja durante la última década y ese declive solo se ha contenido en el caso de los Estados Unidos de América. Esta tendencia subraya la consolidación de la integración de China en la región del TLCAN, basada en el papel estadounidense que resulta fundamental y dinámico. En cambio, China se relaciona con los otros dos países (Canadá y México) siguiendo una estrategia más complementaria, aunque con relaciones intraindustriales en algunos sectores específicos.
En el ámbito del comercio entre China y los Estados Unidos de América, hay 32 capítulos con un IGL superior a 0,5 , pero los capítulos más dinámicos $(84$ y 85$)$ no forman parte de ese grupo. Sin embargo, al analizar el IGL ajustado teniendo en cuenta el desequilibrio comercial, esos capítulos muestran valores altos del índice. Eso sugiere que la mayoría del comercio de China con los Estados Unidos de América es comercio intraindustrial, debido en buena medida a la contribución de los capítulos 84 y 85 (aparatos y artefactos mecánicos y eléctricos, respectivamente). Por otra parte, en el comercio entre China y el Canadá hay 18 capítulos con un IGL superior a 0,5. No obstante, entre 1993 y 2011 disminuyó el IGL y el índice ajustado es inferior a 0,30 . Este hecho indica que la mayor parte del comercio de China con el Canadá es complementario (interindustrial).

El comercio de China con México parece ser de tipo interindustrial, ya que solo 11 capítulos muestran un IGL con un valor superior a 0,5. Además, el IGL ajustado se redujo de 0,63 en 1993 a 0,41 en 2011, con una pronunciada caída desde 1999 (véase el gráfico 6).

El análisis detallado de la mayoría de los capítulos relevantes $(84,85$ y 87$)$, realizado a un nivel más desagregado (partidas), denota con mayor claridad la naturaleza marcadamente intraindustrial de las relaciones de México con los Estados Unidos de América (su principal socio comercial) y China, así como las tendencias vinculadas a la emergencia de China en la región del TLCAN. En particular, el cálculo del IGL ajustado del 
comercio bilateral entre China, los Estados Unidos de América y México con respecto al capítulo 84 evidencia un drástico aumento del comercio intraindustrial entre China y México (véase el gráfico 7). De hecho, durante los últimos años, el comercio bilateral de estos productos (aparatos y artefactos mecánicos) entre México y China ha alcanzado sus valores máximos, cercanos a 1 (es decir, al $100 \%$ de comercio intraindustrial). La comparación con el comercio entre México y el mercado estadounidense, que deja ver un claro estancamiento e incluso un declive con respecto al comienzo del período, plantea nuevas cuestiones, sobre todo si la intensificación del comercio intraindustrial con China ha hecho que se detenga la especialización intraindustrial de México con los Estados Unidos, que se había iniciado con gran vigor a finales de los años noventa. Los datos parecen confirmar esta hipótesis.

Los datos relativos al otro capítulo significativo para el comercio entre México y los Estados Unidos de América, el capítulo 85 (máquinas, aparatos y material eléctrico), indican la consolidación de su acentuada naturaleza intraindustrial (90\% en 2011). En cambio, las otras dos relaciones de comercio bilateral (entre México y China, y entre China y los Estados Unidos de América) revelan estancamiento en la evolución del IGL (véase el gráfico 8). Sin embargo, el IGL relativo al comercio entre China y el mercado estadounidense es superior al del comercio entre China y México, como consecuencia del papel de los Estados Unidos de América como líder del comercio intraindustrial.

Algo muy diferente sucede con el análisis del capítulo 87 (vehículos, partes y accesorios), en el que vuelve a aparecer el marcado carácter intraindustrial del comercio entre México y los Estados Unidos de América, que alcanzó su máximo durante la última década (véase el gráfico 9). Con respecto a las otras dos relaciones comerciales bilaterales, se puede observar un comportamiento más irregular, pero incluso resulta más sorprendente la tendencia a la baja del IGL al final del período. Esta tendencia afecta claramente al comercio entre China y México, así como al comercio entre China y los Estados Unidos de América y reduce los flujos comerciales intraindustriales a niveles muy bajos (cercanos al 10\%). El análisis con un mayor grado de desagregación (cuatro dígitos para vehículos, partes y accesorios) indica que las tendencias relativas a la importación y exportación de motores y accesorios automovilísticos son atribuibles a los menores costos de la mano de obra de las empresas transnacionales en China y al auge de este sector tras el proceso de apertura de la economía de China a comienzos de los años setenta (Cárdenas y Dussel, 2011; Dussel y Gallagher, 2013).

GRÁFICO 7

China, Estados Unidos de América y México: comercio intraindustrial relativo al capítulo $84^{\mathrm{a}}, 1993-2011$

(En valores del índice de Grubel y Lloyd)

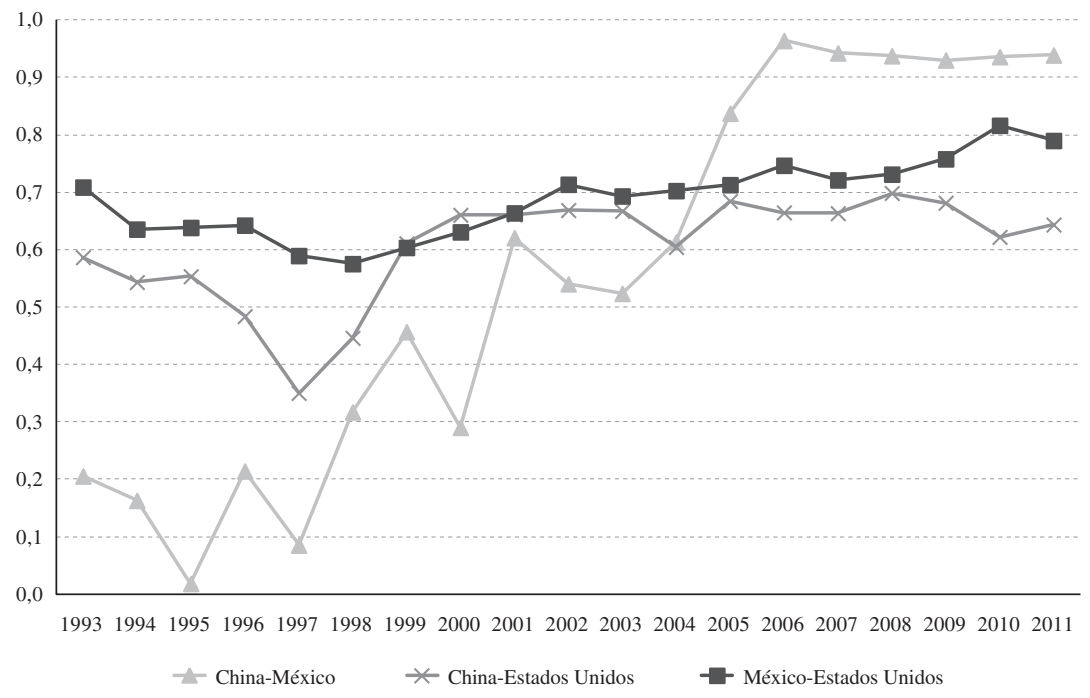

Fuente: elaboración propia a partir de la base de datos COMTRADE de las Naciones Unidas.

a Aparatos y artefactos mecánicos. 
GRÁFICO 8

China, Estados Unidos de América y México: comercio intraindustrial relativo al capítulo $85^{\mathrm{a}}, 1993-2011$

(En valores del índice de Grubel y Lloyd)

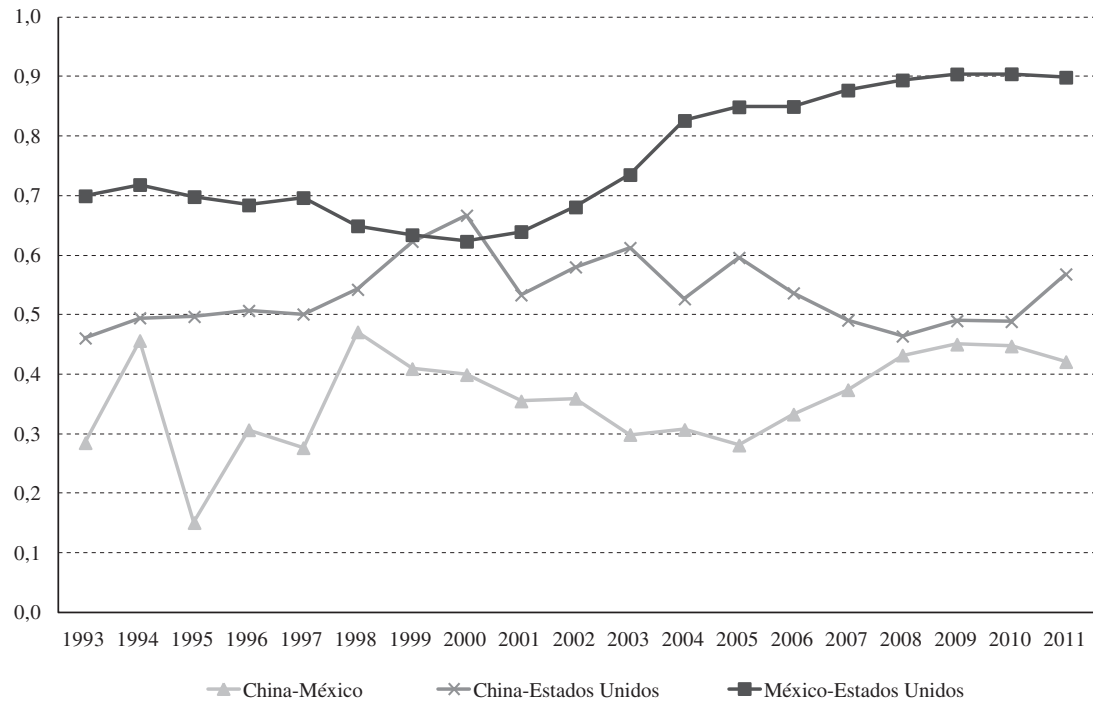

Fuente: elaboración propia a partir de la base de datos comtrade de las Naciones Unidas.

a Máquinas, aparatos y material eléctrico

GRÁFICO 9

China, Estados Unidos de América y México: comercio intraindustrial relativo al capítulo $87^{\mathrm{a}}$, 1993-2011

(En valores del índice de Grubel y Lloyd)

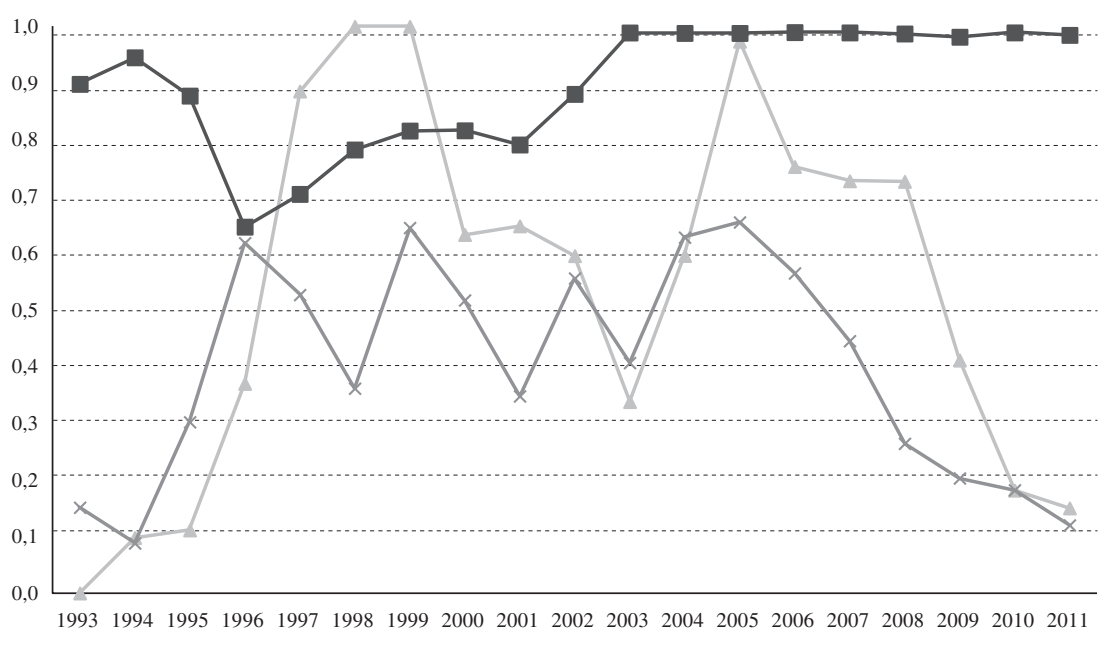

$$
\text { -China-México } \quad \text { CChina-Estados Unidos } \quad \text {-México-Estados Unidos }
$$

Fuente: elaboración propia a partir de la base de datos COMTRADE de las Naciones Unidas.

a Vehículos, partes y accesorios. 
También resulta útil estudiar comparativamente la evolución de las importaciones por parte de los Estados Unidos de América procedentes de China y México en cada uno de los capítulos relevantes (véanse los gráficos 9, 10 y 11). Con la excepción del capítulo 87 (vehículos, partes y accesorios), las importaciones provenientes de China superan en gran medida a las de México ${ }^{8}$. De hecho, los productos originados en China parecen tener un "efecto de sustitución", si bien en muchos casos las importaciones de productos procedentes de México no están cayendo en términos absolutos, lo que significa

${ }^{8}$ En algunos productos específicos esta tendencia está incluso más acentuada, como en el caso de las partidas $8443,8471,8473,8481$ y 8525 . que China está logrando una mayor cuota de mercado en otros países.

Lo anterior no se aplica al capítulo 87 (vehículos, partes y accesorios) ya que, en el gráfico 12, se muestra que México sigue siendo el proveedor (y el cliente) más importante de los Estados Unidos de América en esta cadena de producción. El alto nivel de comercio intraindustrial entre los dos países en este sector refleja, en parte, la descentralización del sector automotor estadounidense. La cuota correspondiente a México del comercio mundial de este sector lo indica claramente: México subió del 2,4\% de las exportaciones mundiales y de un 0,6\% de las importaciones en 1993 al 5,3\% de las exportaciones mundiales y al $2,7 \%$ de las importaciones en 2011 (oMC, 2013).

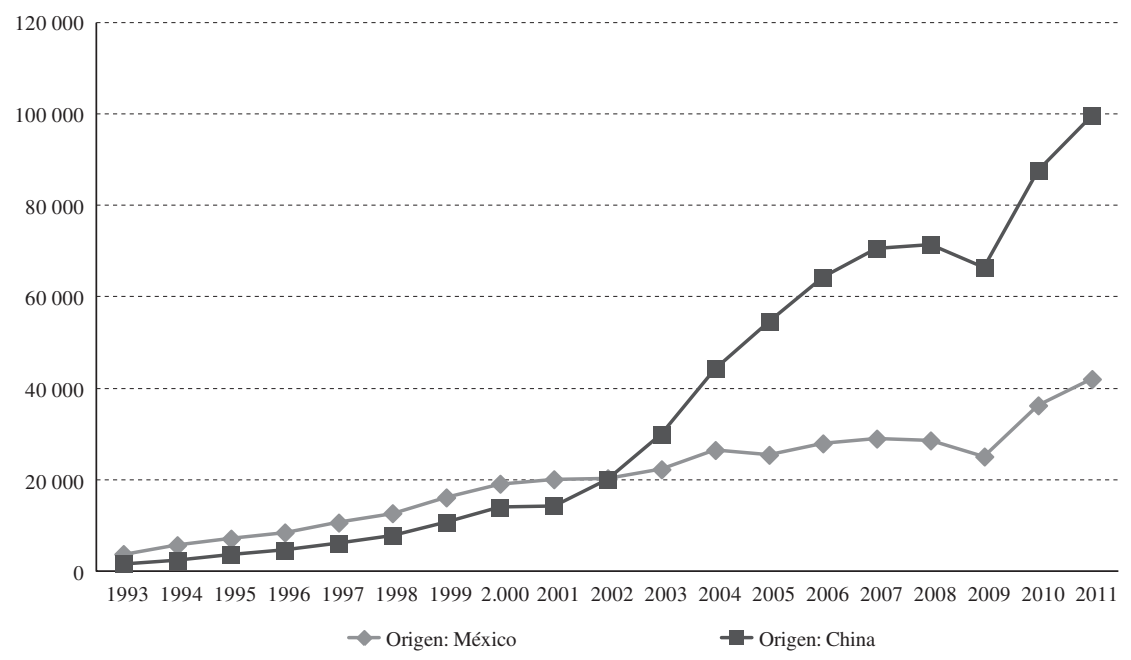

Fuente: elaboración propia a partir de la base de datos COMTRADE de las Naciones Unidas.

a Aparatos y artefactos mecánicos. 
GRÁFICO 11

Estados Unidos de América: importaciones procedentes de China y México de productos del capítulo $85^{a}$, 1993-2011

(En millones de dólares)

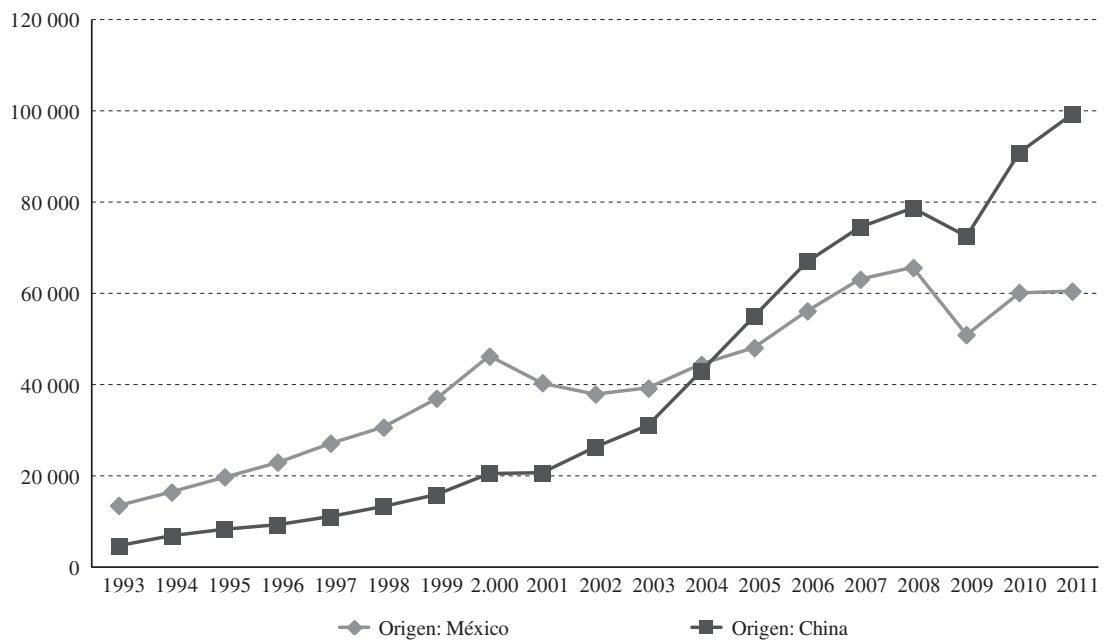

Fuente: elaboración propia a partir de la base de datos COMTRAde de las Naciones Unidas.

a Máquinas, aparatos y material eléctrico.

GRÁFICO 12

Estados Unidos de América: importaciones procedentes de China y México de productos del capítulo $87^{a}$, 1993-2011

(En millones de dólares)

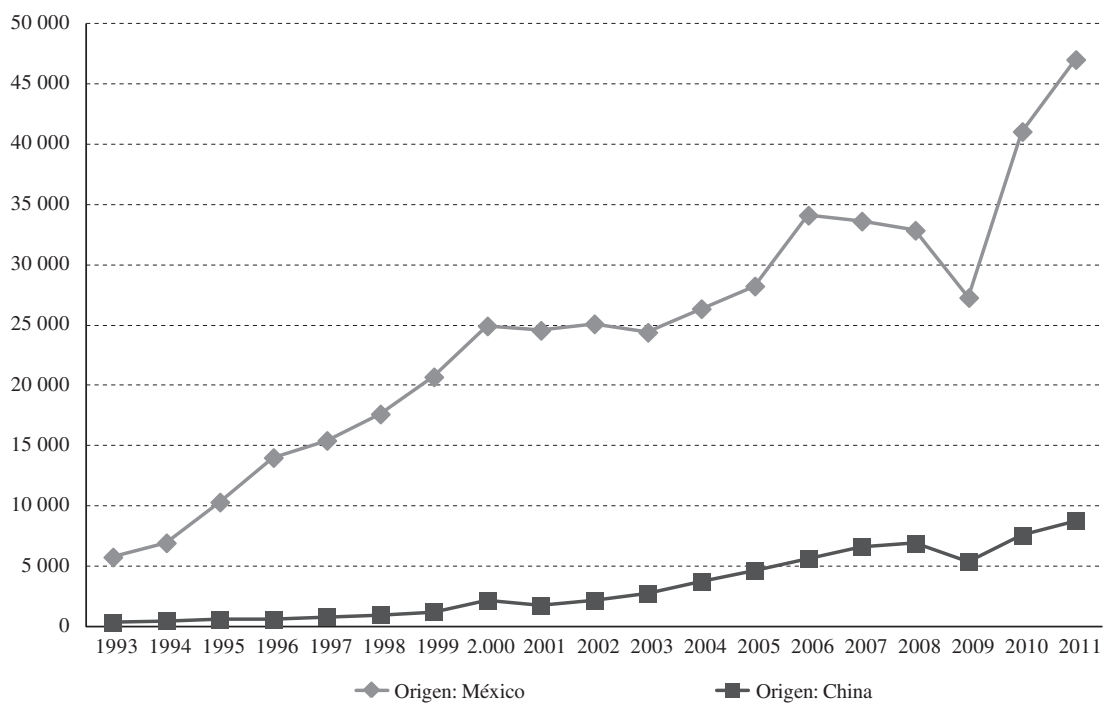

Fuente: elaboración propia a partir de la base de datos COMTRADE de las Naciones Unidas.

a Vehículos, partes y accesorios. 
Estos capítulos constituyen más de la mitad de las exportaciones de México a los Estados Unidos de América y tienen una alta tasa de comercio intraindustrial, lo que muestra la integración de México en las cadenas globales de valor, especialmente en lo referente a las manufacturas, que representan el producto de la "fábrica mundial".

Los mismos capítulos $(84,85$ y 87) de las exportaciones de China al mercado estadounidense constituyen el 49,8\% de las exportaciones totales de China, si bien la tasa de comercio intraindustrial es menor que la de México. China está menos integrada, especialmente con respecto al capítulo 87, en el que predomina el comercio intraindustrial entre México y los Estados Unidos de América. En lo que respecta a esos capítulos, el comercio intraindustrial es más intenso entre México y los Estados Unidos de América que entre este último y China, cuyo comercio tiende a ser de tipo más complementario (comercio interindustrial). Sin embargo, en cuanto al capítulo 84, el incremento exponencial del comercio intraindustrial entre China y México (véase el gráfico 7) podría ser el resultado de un proceso triangular del comercio entre China, los Estados Unidos de América y México.

Además, teniendo en cuenta la gran variedad de productos incluidos en esos capítulos, resulta útil analizar en detalle lo que sucede con los productos principales que cubren. En el gráfico 13 se aprecia el IGL del comercio intraindustrial de los 13 productos más importantes (a nivel de partidas, con desagregación a cuatro dígitos) del comercio de México con su socio comercial principal (los Estados Unidos de América). Se analizaron tres relaciones de comercio bilateral: entre México y el mercado estadounidense, entre México y China y entre China y los Estados Unidos de América. Los resultados muestran la prevalencia del comercio intraindustrial en las relaciones entre México y los Estados Unidos de América, que supera la correspondiente a las otras relaciones bilaterales con respecto a 10 de los 13 productos considerados. Entre ellos, se incluyen las partidas 8536 (aparatos para corte o conexión de circuitos eléctricos), 8708 (partes y accesorios de vehículos automóviles) y 8408 (motores de encendido por compresión, diésel). Las tres únicas partidas con un IGL inferior para estos dos países que para las otras relaciones comerciales bilaterales son las partidas 8409 (partes de motores de encendido por chispa), 8471 (máquinas automáticas para tratamiento o procesamiento de datos) y 8548 (partes eléctricas de máquinas o aparatos).

Además de las partidas mencionadas, el comercio de China con los países del TLCAN incluye las siguientes: 8443 (máquinas impresoras y accesorios), 8473 (partes $\mathrm{y}$ accesorios, excepto fundas, para máquinas de oficina), 8504 (transformadores eléctricos, convertidores estáticos y rectificadores), 8542 (circuitos electrónicos integrados y microestructuras), 8711 (motocicletas y velocípedos equipados con motor auxiliar) y 8712 (bicicletas y demás velocípedos, sin motor). El comercio de estos productos en el caso de China muestra niveles muy bajos de comercio intraindustrial y los flujos son en gran medida unidireccionales.

GRÁFICO 13

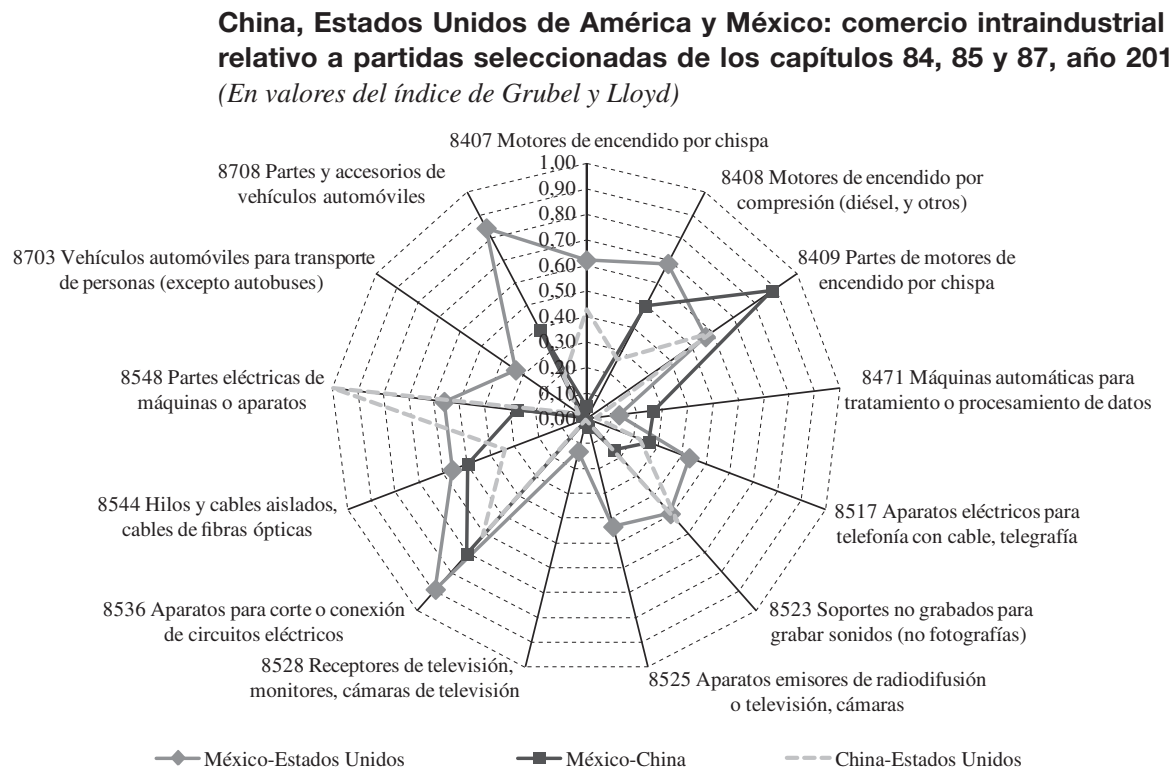

Fuente: elaboración propia a partir de la base de datos COMTRADE de las Naciones Unidas. 


\section{VI}

\section{Conclusiones}

Los resultados obtenidos en este estudio muestran las tendencias y consecuencias principales para el comercio de los países del TLCAN derivadas de la incursión de China en América del Norte. El creciente papel de China a lo largo de la última década confirma su posición como el principal proveedor del mercado estadounidense, con México en segundo lugar. Algo parecido sucede con respecto al comercio de México, cuyo segundo origen principal es China, inmediatamente después de los Estados Unidos de América. De forma similar, China es el segundo mayor proveedor del Canadá, después de los Estados Unidos de América.

Estas tendencias se deben a diversos factores, entre los que destaca el comercio intraindustrial. En particular, el comercio intraindustrial entre México y el mercado estadounidense creció vigorosamente en los primeros años del TLCAN, con un ligero declive entre 2000 y 2011, debido a la recesión de 2001 en la economía de los Estados Unidos de América y a la entrada de China en la OMC, que hizo que se convirtiera en uno de los principales actores de la región.

Desde un punto de vista sectorial, los resultados de este estudio resaltan el crecimiento del comercio intraindustrial relativo a los vehículos, partes y accesorios (capítulo 87), aparatos y artefactos mecánicos (capítulo 84) y máquinas, aparatos y material eléctrico (capítulo 85). El análisis de estos tres tipos de productos, que constituyen más del 52,0\% de las exportaciones totales de México, indica la expansión de la especialización del país en el comercio intraindustrial. El mercado estadounidense es el principal mercado de México y recibe el 82,2\% de sus exportaciones en estos capítulos.

El hecho de que el comercio intraindustrial de los Estados Unidos de América en estos capítulos probablemente vaya a seguir aumentando, y en mayor medida en relación con México que con China, tiene gran relevancia. El comercio intraindustrial horizontal es el intercambio de productos similares pero diferentes y el comercio intraindustrial vertical se refiere a la transferencia de un producto de un país a otro en varias etapas de su desarrollo (comercio intrafirma). México muestra la mayor tasa de comercio intraindustrial, ya que integra ambas modalidades, mientras que el comercio intraindustrial de China es principalmente horizontal, excepto en lo que atañe a los capítulos 84 y 85. Los altos niveles de comercio intraindustrial con México (capítulos 84, 85 y 87) y China (capítulos 84 y 85) indican que estos países forman parte de la "fábrica mundial", cuyo eje central está en los Estados Unidos de América. En el caso de México, la mayor parte de este comercio es intrafirma, como por ejemplo en el caso del sector automotor, en el que México se ha convertido en una potencia mundial. Sin embargo, resulta significativo que ninguna de las empresas que forman ese sector sea mexicana.

En resumen, los resultados indican que el comercio intraindustrial y el intrafirma aparentemente están vinculados de manera estrecha en el caso de México y parecen ser dos caras del mismo proceso: la participación de México en el TLCAN y el paulatino traslado al exterior de la industria de producción de los Estados Unidos de América. Sin embargo, desde la entrada de China en la OMC en 2001, el TLCAN parece haber sido incapaz de crear comercio dentro de su área de influencia, excepto en el sector automotor. Como ya se mostró, China ha logrado una gran penetración en la región del TLCAN, si bien solo ha obtenido niveles significativos de comercio intraindustrial con los Estados Unidos de América. Esto puede deberse a su entrada en la omc, que proporcionó a China un acceso directo al mercado estadounidense. En cambio, el comercio entre China y el Canadá es fundamentalmente interindustrial y, en muchos casos, se vincula a ventajas comparativas tradicionales (patrimonio de recursos). De hecho, el Canadá es el único país del TLCAN con el que China tiene un déficit comercial.

China se ha convertido en la "fábrica mundial" y disfruta de un superávit comercial con todos los países del TLCAN en relación con sus exportaciones dentro de los cuatro capítulos principales (fundamentalmente manufacturas). Sin embargo, también registra un déficit en el comercio de recursos naturales (petróleo) y de materias primas y alimentos (algunos de los cuales forman parte de sus cinco principales capítulos de importaciones). Asimismo, ha logrado introducirse con éxito en la zona del TLCAN, sin necesidad de un tratado de libre comercio ni su reconocimiento como economía de mercado por parte de los países del TLCAN. La zona de libre comercio parece funcionar como una rueda en la que los Estados Unidos de América actúan como eje, mientras que el Canadá, China y México forman los radios. 


\section{Bibliografía}

Balassa, B. (1963), "European integration: problems and issues", American Economic Review, vol. 53, No 2, Nashville, Tennessee, American Economic Association.

Cárdenas, H.L. y E. Dussel (2011), "El comercio intraindustrial en México: Un comparativo entre China y Estados Unidos", Comercio Exterior, vol. 61, $\mathrm{N}^{\circ} 4$, julio-agosto.

CEFP (Centro de Estudios de las Finanzas Públicas) (2006), Comentarios al informe en materia arancelaria, 2005, CEFP/022/2006, México, D.F.

De la Cruz, J. y C. Marín (2011), "El impacto de China sobre América Latina en el mercado de Estados Unidos, un análisis de causalidad", Perfil de Coyuntura Económica, N 18, Medellín, Universidad de Antioquia.

De la Cruz, J., J.A. Núñez y A. Ruiz-Porras (2008), "El impacto de la inversión extranjera directa de Estados Unidos en América Latina y China: Evidencia empírica de causalidad", Globalización y regionalismo: Economía y sustentabilidad, A. Ivanova y A. Guillén (coords.), México, D.F., Editorial Miguel Ángel Porrúa.

Dornbusch, R. (1992), "En defensa de la apertura comercial en los países en desarrollo", Análisis Económico, vol. 10, $\mathrm{N}^{\circ}$ 20, México, D.F., Universidad Autónoma Metropolitana Azcapotzalco (UAM-A).

Dussel, E. y K.P. Gallagher (2013), "El huésped no invitado del TLCAN: China y la desintegración del comercio en América del Norte", Revista CEPAL, N 110 (LC/G.2572-P), Santiago de Chile.

Dussel, E. y A. León González (2001), "El comercio intraindustrial en México, 1990-1999”, Comercio Exterior, vol. 51, N 7 , México, D.F, julio.

Dussel, E. y Y. Trápaga (coord.) (2007), China y México. Implicaciones de una nueva relación, México, D.F., Jornada Ediciones.

Feenstra, R. y H. Looi Kee (2009), "Trade liberalization and export variety: a comparison of Mexico and China", China's and India's Challenge to Latin America. Opportunity or Threat?, D. Lederman, M. Olarreaga y G. Perry (eds.), Washington, D.C., Banco Mundial.

Gaceta Parlamentaria (2012), "Informes sobre el uso de la facultad conferida al Ejecutivo federal en materia arancelaria, que se presenta de conformidad con el artículo 131 de la Constitución Política de los Estados Unidos Mexicanos", año 16, N 3662-D, Palacio Legislativo de San Lázaro, 7 de diciembre.

Gazol, A. (2007), "Un nuevo tipo de proteccionismo (o el retorno del permiso previo)", Economía UNAM, vol. 4, № 12, México, D.F., Universidad Nacional Autónoma de México.

Grossman, G.M. y E. Helpman (1990), "Trade, innovation and growth", American Economic Review, vol. 80, ํㅜㄹ, Nashville, Tennessee, American Economic Association.

Grubel, H.G. (1967), "Intra-industry specialization and the pattern of trade", Canadian Journal of Economics and Political Science, vol. $33, \mathrm{~N}^{\circ} 3$, Wiley.

Grubel, H.G. y P.J. Lloyd (1971), "The empirical measurement of intra-industry trade", Economic Record, vol. 47, N 4, Wiley.

Hamilton, C. y P. Kniest (1991), "Trade liberalization, structural adjustment and intra-industry trade: a note", Weltwirtschaftliches Archiv, vol. 127, $\mathrm{N}^{\circ} 2$.
Helpman, E. (2006), "Trade, FDI, and the organization of firms", Journal of Economic Literature, vol. 44, $\mathrm{N}^{\circ} 3$, Nashville, Tennessee, American Economic Association.

JETRo (Organización Japonesa para el Comercio Exterior) (2010), 2010 JETRO Global Trade and Investment Report. A Global Strategy for Japanese Companies to Open New Frontiers in Overseas Markets, Tokio.

Krugman, P. (1995), "Growing world trade: causes and consequences", Brookings Papers on Economic Activity, vol. 26, $\mathrm{N}^{\circ}$, Washington, D.C., The Brookings Institution.

López, J.A. y O. Rodil (2008), "Comercio intrandustrial e intrafirma en México en el contexto del proceso de integración de América del Norte (1993-2006)", Economía UNAM, vol. 5, N 13, México, D.F., Universidad Nacional Autónoma de México.

Navaretti, G.B., J.I. Haaland y A. Venables (2002), Multinational Corporations and Global Production Networks: the Implications for Trade Policy, Londres, Centro de Investigación sobre Políticas Económicas.

Neme, O. (2006), La competencia entre México y China: La disputa por el mercado de Estados Unidos, México, D.F., Universidad Nacional Autónoma de México (UNAM)/Miguel Ángel Porrúa.

oCDE (Organización de Cooperación y Desarrollo Económicos) (2002), "Intra-industry and intrafirm trade and the internalization of production", OECD Economic Outlook, $\mathrm{N}^{\circ} 71$, París.

OMC (Organización Mundial del Comercio) (2013), "Estadísticas del comercio internacional, 2012" [en línea] http://stat.wto. org/StatisticalProgram/WSDBViewData.aspx?Language=E.

Rodil, O. y J.A. López (2011), "Efectos del Tratado de Libre Comercio de América del Norte sobre el comercio de México: Creación de comercio y especialización intraindustrial", Revista de Economía Mundial, vol. 27.

Rodríguez-Pose, A. y G. Petrakos (2004), "Integración económica y desequilibrios territoriales en la Unión Europea", EURE, Revista Latinoamericana de Estudios Urbanos Regionales, vol. 30, $\mathrm{N}^{\circ} 89$, Santiago de Chile, mayo.

Rosales, O. y M. Kuwayama (2012), China y América Latina y el Caribe. Hacia una relación económica y comercial estratégica, Libros de la CEPAL, N ${ }^{\circ} 114$ (LC/G.2519-P), Santiago de Chile, Comisión Económica para América Latina y el Caribe (CEPAL), marzo. Publicación de las Naciones Unidas, $\mathrm{N}^{\circ}$ de venta: S.12.II.G.2.

Verdoorn, P.J. (1960), "The intra-bloc trade of Benelux", Economic Consequences of the Size of Nations, E.A.G. Robinson (ed.), Nueva York, Macmillan.

Viner, J. (1950), The Customs Union Issue, Nueva York, Carnegie Endowment for International Peace.

Wang, J. (2004), "China's Changing Role in Asia", Washington, D.C., Atlantic Council [en línea] http://www.acus.org/ docs/0401China_Changing_Role_Asia.pdf.

Yu, Ch., L.X. Xue y S. Hong (2006), "China y los acuerdos de libre comercio", Revista del CEI. Comercio Exterior e Integración, $\mathrm{N}^{\circ} 7$, Buenos Aires, Centro de Economía Internacional (CEI), diciembre. 